\section{Rift Valley fever in the Horn of Africa: challenges and opportunities}

\author{
Nicole Butcher, Melissa Tan, \\ Mohamud Sheikh \\ School of Public Health \& Community \\ Medicine, University of NSW, Kensington \\ NSW, Australia
}

\section{Abstract}

The Rift Valley fever (RVF) epidemic in the Horn of Africa region in 2007 resulted in significant mortality on a background of protracted political instability, famine, food insecurity and internal population displacement. Communicable diseases such as RVF are difficult to contain in such a context with protracted civil war, statelessness, poor governance and constant population movement. A literature review was conducted to assess i) contributing factors to the latest RVF crisis and ii) emergency response. Within the review, the challenges and opportunities for future management were also identified. A range of geopolitical, socioeconomic and environmental barriers impeded the public health response, notably the lack of regional epidemic management guidelines. The Horn of Africa nations did not have localized response plans despite the presence and assistance of multinational organizations with epidemic containment strategies. Traversing borders and boundaries, RVF could wreak devastating outcomes once more unless stringent local and regional public health collaborations are established. It is therefore necessary to empower livestock owners and instate them in national and regional early detection, as part of a strengthened detection and response mechanism.

\section{Introduction}

Following unusually heavy rainfall in mid December 2006, the Kenyan Ministry of Health received reports of unexplained fatalities associated with fever and generalized bleeding in Garissa, Kenya's North East Province (NEP). More deaths followed later in the month, and livestock deaths and unexplained animal miscarriages were being reported from the same area. By 25 January 2007, 404 human cases of Rift Valley fever (RVF) and 118 deaths had been recorded. ${ }^{1}$

RVF had reappeared as the zoonotic virus that, ten years prior, was responsible for approximately 89,000 cases and 478 deaths ${ }^{1}$. the largest reported human outbreak of the disease. Similarly, the 1997 NEP-centered outbreak occurred when exceptionally heavy rains filled much of Kenya with floodwaters.

\section{Rift Valley fever}

RVF is endemic in the Horn of Africa countries, where epidemics have only occurred in rural areas. ${ }^{2}$ Outbreaks have been noted every ten to twenty years since the fever was first identified in sheep in Kenya in 1931. ${ }^{3}$

Associated with the virus are: heavy rainfall, highly active reservoir vectors and susceptible livestock having human contact. ${ }^{4}$ During heavy rainfall, a large number of larvae sites become flooded and the unusually high hatching of mosquitoes promotes disease transmission to animals via increased vector bites and subsequently to humans primarily via infected animal exposure. ${ }^{5}$ The Aedes mosquito is the inter-epizootic reservoir, capable of transovarial transmission, ${ }^{6}$ which accounts for the ongoing survival of the virus in dry conditions between epizootics and epidemics. ${ }^{1}$

RVF typically has a case fatality rate of $1 \%$, with significant morbidity also resulting from meningoencephalitis and ocular involvement. $^{2}$ In the 2006-07 epidemic, the devastating case fatality rate in Kenya was $23 \%$ of 684 reported cases between November 2006 and March 2007. ${ }^{7}$ In neighboring Somalia, it was as high as $45 \%$ of the 114 reported cases between 19 December 2006 and 20 February $2007,{ }^{7}$ if the reports were accurate.

\section{Methods of research}

Reports and reviews specific to the 2006-07 RVF outbreak were gathered and a literature review conducted. First, Checchi et al.'s hostagent-environment framework was used to assess risk factors that contributed to the proliferation of the virus. Next, an assessment of the emergency response measures was made with consideration also given to the situational challenges. Finally, prior appraisals of the outbreak's management were gathered for comparison with Connelly et al.'s evidencebased principles of outbreak control.

\section{Findings}

\section{Risk factors}

The high mortality evidenced in 2006-07 can be traced to numerous risk factors on all levels (proximate, intermediate and distal) of the host-agent-environment framework of the disease. ${ }^{8}$ Political instability and population movement, delayed public health response and lack of pre-existing management guide-
Correspondence: Nicole Butcher, Associate Medical Editor, c/o Ponleu Sokhapheap, \# 34, Street 304, Sangkat Olympic, Chamkarmon, Phnom Penh, Cambodia. Tel. +855.12.940.881.

E-mail: butcher.nicole@gmail.com

Key words: Rift Valley fever, emergency response, public health challenges, prevention and control.

Contributions: NB, MT topic research, literature review, manuscript writing and editing; MS literature review, manuscript writing and revision.

Conflict of interests: the authors report no conflict of interests.

Received for publication: 11 May 2011.

Revision received: 14 July 2011.

Accepted for publication: 28 July 2012.

This work is licensed under a Creative Commons Attribution NonCommercial 3.0 License (CC BYNC 3.0).

(C) Copyright N. Butcher et al., 2012

Licensee PAGEPress, Italy

Journal of Public Health in Africa 2012; 3:e24

doi:10.4081/jphia.2012.e24

lines are notable contributors. Unusually heavy rainfall provided perfect conditions for the ten-year re-appearance of RVF. Mosquito vectors were in abundance, and the virus lived up to its renowned ability to take advantage of the humidity.

Lack of protective equipment accounted for the morbidity and mortality evidenced in some occupational groups. Farmers and butchers were exposed through animal slaughter processes and veterinarians through instrumental procedures. It was male livestock herders aged 21-30 who first experienced infection followed by women in the same age bracket, yet this is likely to be due to handling meat. Over time, the distribution of cases expanded to other age groups and sexes, although cases involving children under five years and older persons (50 years plus) were rare. ${ }^{1}$ Outbreak maps ${ }^{9}$ demonstrate that exposure progressed rapidly to disease in the region, no doubt in strong association with the populations' malnourishment and minimal access to health care. Transmission to non-affected areas would also have been promoted by human and livestock movements, which were driven by civil, political and food insecurity. ${ }^{6}$ In the crowded environments of refugee settlements, the vectors had ample chance to thrive.

\section{Emergency response}

Neither management guidelines nor a regional agreement for RVF prevention existed at the time of the outbreak, so the infec- 
tion had time to spread before a response was mounted. ${ }^{4}$ The health and agriculture sectors in the affected countries were unprepared to manage the epidemic since they had few mechanisms of surveillance, prevention and disease control. Once control measures began, they were directed towards current epidemic management and the development of future epidemic preparedness. ${ }^{1}$ Epidemic response involved the Ministry of Health and Department of Veterinary Services of affected countries in collaboration with several reputable international health organizations. It included: community education via radio, public meetings and community leadership forums; animal and vector control; ${ }^{2}$ clinical case management; and, staff training and community mobilization. ${ }^{1,7}$

Public education warned against drinking raw milk, and eating uninspected meat, ${ }^{10}$ aiming to minimize transmission and exposure. Livestock movement and export were restricted, animal slaughter was banned and quarantine implemented for infected animals. ${ }^{10}$ Vector management involved indoor residual spraying, larviciding ${ }^{10}$ and the provision of treated bed nets. ${ }^{7}$ Constituting a direct obstacle to active response, however, was the ongoing flooding that damaged frail infrastructure and multiplied logistical difficulties, particularly in terms of supplies, access, transportation and communications. ${ }^{7}$

Clinical management extended beyond case treatment to the establishment of RVF wards, diagnostic facilities, stock provision and infection control procedures. The training provided to health personnel covered RVF detection and management, and public education regarding the disease and precautionary behaviors mentioned earlier. Nevertheless, civilians who were concerned primarily with addressing the personal consequences of food and economic instability engaged in risk-taking behaviors such as non-compliance with animal handling recommendations. ${ }^{6}$ The banning of livestock slaughter had damaged their livelihoods and consequently affected markets and the meat industry. ${ }^{10}$

Preparing for the future, strategies were (and are still being) developed for epidemic surveillance, prevention and management in the region, including a national RVF response plan and management guideline in Kenya.

\section{Challenges of the outbreak response}

In combination with the risk factors for outbreak, it was the scarcity of resources, technical capacity and coordination that militated against response efforts. Owing to the lack of functional government and health facilities, there was rather inaccurate, incomplete and uncertain data informing response teams. They could not easily obtain basic demographic or population movement information. Given this and the absence of local and regional agreements around RVF epidemics and their management, service delivery was scarce in remote or isolated areas and among oppressed and/or nomadic populations. ${ }^{10,11}$

Geopolitical dynamics were an important component of the predicament. The ongoing civil war in Somalia with Kenyan-Somali border closures during the epidemic heavily obstructed timely outbreak investigation, resource allocation, division of responsibilities, shared communications, contingency planning and referral system agreements. ${ }^{4,7}$ National resources were depleted and the imperative of public health held little weight in this climate.

\section{Opportunities}

In war-affected resource-poor populations, the three key components of humanitarian response are: prevention and control of communicable diseases; case management; and, surveillance. ${ }^{12}$ Commentators on the RVF outbreak in 2006-07 echo this principle in their recommendations for RVF prevention at the epidemic foci level, calling for: strengthened surveillance, the establishment of early detection mechanisms; and the optimisation of case management, health education and vector control efforts. ${ }^{12,13}$ In particular, one weakness noted in communication channels presents an opportunity for strengthened surveillance. It has been noted that WHO's global early warning system, in November 2006, alerted countries' authorities to the climatic events that would trigger the proliferation of vectors but this warning did not elicit timely resource mobilization. ${ }^{7}$ It was later reported that livestock owners had meanwhile recognized the characteristics of RVF in their flocks. ${ }^{10}$ Since agro-farmers readily notice agricultural, climatic and livestock abnormalities, they are in a position to detect an outbreak sooner than institutional surveillance systems. Therefore, strengthened surveillance at the community level is an area where there is great potential to embrace the principles of outbreak prevention and control. In fact, early warning signaling relies on the systematic combination of farmers' observations and national monitoring technology.

\section{Discussion}

What compromised the efficiency and coordination of the public health response in 2006-07 was a range of complex geopolitical, socioeconomic and environmental barriers; the very circumstances in which outbreaks often arise. ${ }^{14}$

The public health response was significantly hindered by the lack of prior agreement and coordination mechanisms regarding RVF epidemic management between neighboring countries. Regional guidelines are a crucial requirement for the success of future epidemic management, for cohesive and uniform public health measures and efficient mobilization of resources across affected regions, irrespective of political borders. Other key opportunities for improvement involve early warning systems through local surveillance, established communication lines for community public health education and established regional medical guidelines. Future response preparedness can therefore be strengthened in the establishment of a state-sanctioned mechanism of forecast-based warnings of flooding events merging with early (local, livestock owners') detection of disease vectors to jointly activate national reinforcements in the way of widespread monitoring, active disease surveillance and pre-emptive public health measures, including public education and clinician refresher training for case management and infection control. These early responses would also help begin preliminary mobilization of resources, such as medical supplies and animal vaccinations, which take several months to procure. By calling all stakeholders to action, therefore, this response mechanism could ultimately mitigate an epidemic. ${ }^{10}$

\section{Conclusions}

The Horn of Africa Rift Valley fever epidemic of 2006-07 demonstrated the disastrous potential of communicable disease epidemics in politically unstable, resource-poor regions with fragile public health systems. The high mortality rate associated with this epidemic illustrates the imperative of epidemic preparedness and international cooperation for communicable disease control. Before the next outbreak of RVF, likely to occur in around 2016 unless hastened by the effects of global climate change, there is a window of opportunity to enhance the current capacity for response. It requires the establishment of regional and national detection and response systems that incorporate the principles of communicable disease management in complex environments. While negotiations towards comprehensive regional agreements will no doubt be lengthy, the on-the-ground insight of farming and rural communities must be harnessed to minimize human and animal populations' risk of exposure to disease. 


\section{References}

1. Centers for Disease Control and Prevention. Rift Valley fever outbreak Kenya, November 2006 - January 2007 [Internet]; updated 2 February 2007. http://www.cdc.gov/mmwr/preview/mmwrh $\mathrm{tml} / \mathrm{mm} 5604 \mathrm{a} 3$.htm Accessed: December 4, 2010.

2. World Health Organization. Rift Valley fever: Fact sheet no. 207 [Internet]; updated May 2010. http://www.who.int/mediacentre/factsheets/fs207/en/\# Accessed: December 4, 2010.

3. Consultative group for RVF decision support. Decision-support tool for prevention and control of Rift Valley fever epizootics in the greater Horn of Africa. Am J Trop Med Hyg 2010;83 Suppl 2:S75-85.

4. World Health Organization. Rift Valley fever outbreaks forecasting models [Internet]; 2009. http://whqlibdoc.who. int/hq/2009/WHO_HSE_GAR_BDP_2009.2 _eng.pdf Accessed: January 18, 2011.

5. Centers for Disease Control and
Prevention. Rift Valley fever fact sheet [Internet]; 2007. http://www.cdc.gov/ncidod/dvrd/spb/mnpages/dispages/Fact_Shee ts/Rift_Valley_Fever_Fact_Sheet.pdf Accessed: January 17, 2011.

6. World Health Organization. Horn of Africa: emergency-affected countries [Internet]; 2007, Report number: WHO/CDS/ NTD/DCE/2007.1. http://www.who.int/diseasecontrol_emergencies/toolkits/who_cd s_ntd_dce_2007_1/en/index.html Accessed: January 19, 2011.

7. World Health Organization. Weekly epidemiological record [Internet]; 2007 http://www.who.int/wer/2007/wer8220/en/i ndex.html Accessed: January 17, 2011.

8. Checchi F, Gayer M, Grais R, Mills E. Public health in crisis-affected populations: a practical guide for decision-makers. London: Overseas Development Institute; 2007. Network Paper 61.

9. World Health Organization. Communicable disease epidemiological profile for Horn of Africa [Internet]; 2007. http://www.who.int/wer/2007/wer8220/en/i ndex.html Accessed: January 17, 2011.
10. Jost C, Nzietchueng S, Kihu S, et al. Epidemiological assessment of the Rift Valley fever outbreak in Kenya and Tanzania in 2006 and 2007. Am J Trop Med Hyg 2010;83 Suppl 2:S65-72.

11. Seufi A, Galal F. The role of Culex and Anopheles mosquito species as potential vectors of Rift Valley fever virus in the Sudan outbreak, 2007. BMC Infect Dis 2010;10:65.

12. Connelly M, Gayer M, Ryan M, et al. Communicable diseases in complex emergencies: impact and challenges. Lancet 2004;364:1974-83.

13. Hassanain A, Noureldien W, Karsany M, et al. Rift Valley fever among febrile patients at New Halfa Hospital, Eastern Sudan. Virol J 2010;7:97.

14. World Health Organization. Framework for global outbreak alert and response [Internet]; 2001. Report number: WHO/CDS/ CSR/ISR/2000.2. Available from: http://www.who.int/ csr/resources /publications/surveillance/WHO_CDS_CS R_2000_2/en/ Accessed: January 19, 2011. 